\title{
Changes in the Content of the Technology Subject and Students' Learning Achievements
}

\author{
Marijana Juralovich \\ Faculty of Natural Sciences, Didactics of Household Culture, Vilnius Pedagogical University, Vilnius, Lithuania
}

\section{Email address:}

juralovic@bk.ru, marianajuralovic@gmail.com

\section{To cite this article:}

Marijana Juralovich. Changes in the Content of the Technology Subject and Students' Learning Achievements. International Journal of Education, Culture and Society. Vol. 6, No. 4, 2021, pp. 120-128. doi: 10.11648/j.ijecs.20210604.14

Received: June 24, 2021; Accepted: July 16, 2021; Published: July 27, 2021

\begin{abstract}
Based on Lithuanian and foreign scientific, pedagogical and psychological literature, normative state documents, the article identifies the importance of personality development during technology lessons, taking into account gender. The author analyzes the problems of technological subject content change in the development of children's social and technological competencies, which have a direct impact on the internalization of personality values and the fostering of creativity. The shortcomings of the education system, on which the unequal educational attainment of students of different genders depends, are also examined. The results of the student and teacher survey and recommendations are provided to suggest ways to reduce these differences. A person's inclinations and abilities are determined by nature and upbringing. A child's development is inextricably linked to both of these factors. Nature is the most important factor influencing gender-specific behavior, but experience, practice, and interaction with others also affect neurons and brain connections. Technology lessons and studies are a great medium to encourage students' (young people's) creative beginnings, develop their creativity, positive thinking, implement moral values and strengthen motivation for science. The subject of technology is the only thing whose change in content has helped to refine the natural teaching (learning) of boys and girls and to draw attention to the differences in their teaching and learning achievements in other subjects as well. There is currently a lack of subject didactics research to help understand how to effectively teach different subjects to students of different genders. Coordinated efforts should be made in Lithuania and around the world to encourage boys and girls to reach their full potential. It is therefore necessary to change the education strategy. Reduce the study load in subjects, give up homework or replace homework with creative projects or longterm tasks. Children's brain circuits have a certain period of puberty and are psychologically unprepared for information and workload not according to their age and nature. Stop forming a "fear" attitude towards science for students who are being prepared for their twelfth grade exams from the first grade.
\end{abstract}

Keywords: Creativity, Technology Subject Programs, Personality Development According to Gender, Learning Motivation, Teaching / Learning Achievements

\section{Introduction}

In accordance with the State Education Strategy for 20132022 (hereinafter - the Strategy), the strategic planning of Lithuanian education has continued, and the efforts of the education community are focused on fundamental changes in education that meet public expectations, basic state needs and global education trends. Taking into account the aspiration of the Lithuanian Progress Strategy "Lithuania 2030" to create a smart, i.e. active, solid, learning, society, the essential task of education is set in the Strategy - to mobilize the educational community and all Lithuanian people (solidarity) for continuous purposeful education (learning) for personal and national success (activity), ensuring equal opportunities. According to international student achievement surveys, girls in Lithuania usually achieve better learning outcomes (especially the large gap between boys and girls' reading skills), and student achievement in rural and urban schools differs significantly. These are the challenges that need to be overcome in order to significantly improve the achievements of the country's students [27]. Compared to the OECD and EU countries, Lithuania is one of the countries with the greatest lack of gender balance in the distribution of teachers and lecturers. $<\ldots>$ The strategy aims to increase the number 
of male teachers in primary and secondary education. It is believed that more male teachers can help improve student achievement (mostly boys), that gender balance is needed in school as well as in society, that male teachers can become a model of the male role for boys. However, no progress has been made in implementing the strategy's goal, as the number of male teachers working in primary and secondary education programs decreased between 2013 and 2016.<..> Gender mainstreaming should be included in teacher education and training programs. There is currently a lack of subject didactics research to help understand how to effectively teach different subjects to students of different genders.

While the traditional issue of girls' access to education remains quite sensitive in many parts of the world, it is no longer so one-sided in Europe, North America and some other more developed regions. In Lithuania, as in most European countries, there are areas of education where it is necessary to take more care of girls' learning opportunities, but in other areas, boys' learning is more of a concern. The UNESCO Education Report (2007) identifies the increasing absenteeism of boys and the low educational attainment as a growing problem in secondary education related to the gender difference. It is also relevant in Lithuania $<\ldots>$ [28].

The subject matter of technology in various aspects has been studied by different scientists for many years. Looking at the "history" of technology, it can be stated that it lost students' interest during the course of the subject's curriculum. The noble goal of "preserving the subject" in various ways: reorganizing the curriculum in university and school curricula, creating only mixed groups of students, did not preserve the subject of technology at university and reduced learning motivation among pupils and students [25].

To update the Technology... program, for example, twentyfour European universities (Germany, Greece, the United Kingdom, Finland, Estonia, Latvia, and so on) were asked to provide more detailed information on the same or similar courses of study at their respective universities programs. In summary, programs differ in terms of content, as well as the qualifications awarded. The results of the study performed by A. Numgaudienè, B. Žygaitiené $[35,36]$ coincide with the results of D. Pendergast et al. [20], identifying differences and similarities in the content of study programs.

Technology lessons and studies are an excellent medium for encouraging students' (young people's) creative beginnings, developing their creativity, positive thinking, implementing moral values, and reinforcing their motivation for science. According to P. Geoff [21], quality is created by strategy, so let's create a happy future "through the eyes of the younger generation". Twenty percent of what we do determines $80 \%$ of the results, so let's work harder rather than harder, focusing on the factors that determine the results. Smart education is a field of social pedagogy that initiates and expands the cognitive process, helps young people to unleash their creative potential and operates in the socioecological community, encompassing all sectors and community activities in which social industries can be formed or initiated [26].
The subject of technology is the only thing whose change in content has helped to refine the natural teaching (learning) of boys and girls and to draw attention to the differences in their teaching and learning achievements in other subjects as well. These differences in teaching and learning have existed for many years in the education systems, in Lithuanian and world schools. In Lithuania, no significant research or work has been done on how to effectively teach students of different genders in various subjects. Schools lack an understanding of how to effectively teach different subjects to students of different genders. For this reason, one of the priority directions in updating the curriculum is to develop scientific potential in Lithuanian higher education institutions by training teachers on this topic. This will help to overcome differences in student achievement and increase social inclusion. It is necessary to provide scientifically based methods and tools for the successful implementation and development of this practice.

The aim is to analyze the links between changes in the content of technology and the assessment of students' subjects, identifying the shortcomings of the education system on which the different learning achievements of students of different genders depend.

\section{Research Methods}

Theoretical empirical research methods: quantitative (student questionnaires) and qualitative (interviews with students, observation, preparation and implementation of short-term and long-term projects, action research). The Social Sciences (22) for Windows spreadsheet program was used to graphically represent the study's findings.

\section{Theoretical Substantiation of the Research}

$<\ldots>$ According to data from national learning achievement surveys, one of the most significant factors affecting student achievement is a lack of metacognitive skills. As shown by IEA TIMSS, IEA PIRLS, LRŠMM, NMPT, NEC studies over 17 (seventeen) years (2002, 2003, 2004, 2005, 2006, 2007, 2008, 2009, 2010, 2011, 2012, 2013, 2014, 2015, 2016 (PIRLS), 2017, 2018), nationally and globally (PIRLS research), there are significant differences in learning outcomes between girls and boys. The analysis and reflection of these results is important in solving the issues of ensuring equal opportunities to acquire a quality education. Dr. Pranas Gudynas [10-13], who focuses on monitoring student performance, argues that certain gender differences are absolutely innate. Recent research in neurology, neurophysiology, neuropsychology, neuroanatomy, neurobiology, etc., has confirmed gender differences in the brain, leading to the establishment of separate classes and even schools for girls and boys in many countries (USA, UK, Singapore, Israel, Russia, etc.). The most well-known, discussed and analyzed in Lithuania are: 1) audible (audible, 
auditory); 2) visual (visible, observable); 3) kinesthetic (motion, tactile). The learning styles of girls and boys have become increasingly popular in the last decade. $<_{\ldots} .>$ In various countries (Scandinavia, the United States, and Switzerland), the most advanced schools have abandoned $<\ldots>$ grades and teacher dominance in the classroom. Only by opening the school door do seven-year-old boys and girls already differ in their biological development. The boys are almost 6 months behind their classmates. This gap will widen further in adolescence, when peers will overtake boys with their biological maturity and social and communication skills for two years. Under fully individualized education, this crucial maturity gap for adolescent learning could be alleviated and even avoided. $<\ldots>$ The educational process in Lithuanian schools is usually focused on speaking-listening, verbal communication and information exchange, and peaceful cooperation. Such learning requires concentration, calm, attention, discipline, and adherence to established rules. This is not a problem for girls, as they easily adapt to the existing conditions. <...> Boys' bodies produce less serotonin, causing them to act more impulsively. They can't sit in one place for long. They have a hard time concentrating. The autonomic nervous system causes wakefulness when they are standing or moving. Boys need tasks that require movement and spatial thinking, visual and non-verbal learning tools, physical activity in the learning process, and, as much as possible, project-based and research-based teaching, as this not only teaches them to work collaboratively, but also provides opportunities to be active in their own learning style. Challenging, overcoming a problem, self-researching, and finding answers are especially beneficial for boys in situations where blood flow to the brain increases, aiding concentration. Dr. J. Dudaite, together with Dr. Aiste Elij's analysis of the TIMSS test confirmed that boys taught by a male teacher had higher learning achievements $<\ldots>$. The situation and well-being of boys would change if deep educational and individualization were implemented in school. <...> Education would take place through all learning styles (especially kinesthetics). According to research, traditional teaching and learning methods - reading, writing, storytelling, exercises $\langle\ldots>$ continue to dominate the teaching process. These are common but mostly learning methods that require left hemisphere activity. When learning material is presented in a variety of ways and all of the senses are involved in the learning process, students are better able to relate new information to what is already available, discover connections between objects or phenomena, and absorb new materials. Scientists believe that the origins of empathy can be found in a complex system known as mirror neurons $<\ldots>$. The more opportunities you give your child's brain to think about others, the more his or her ability to empathize will develop $\langle\ldots>$. When children can make the right decisions, govern, be empathetic, and understand themselves, they develop a strong and well-functioning sense of morality, one that not only allows us to understand what is good and what is bad, but strives for greater good beyond individual needs.

\section{Brain Biology (Girl / Woman, Boy / Man)}

L. Brizendine, a doctor, conducted research on female and male brain and nervous behavioral systems <... . They include material from neuropsychology, cognitive neurology, child development research, brain imaging, and psychoneuroendocrinology research. According to $\mathrm{L}$. Brizendine $[5,6],<\ldots>$ a woman's and a man's brains are not identical. Butler [2], Simon [37], Brebner [7], Britton [4], Kring [23], Samter [38], Leresche [31], Nagy [34], Cahill [8], Phelps [22], Goldstein [14], Gray [9] have all stated this. Kaufmann [17], Li [33], Kendler [24], Tessitore [40], Lobo [32], Bloch [3], Skurvydas [39], Pease [18, 19], Lekavičiené et al., [30], Grant, [15, 16], Lapukauskas [29], Baron-Cohen [1], Wager [41]. Let's explore brain differences. A man's brain is 9 percent larger, even in terms of body weight. $<\ldots>$ Male and female brain cells are the same. It is in the brains of women that the cells are more densely packed, stuffed into a smaller skull, like a corset. Gender mental differences can be caused by specific chemical processes in a woman's brain. L. Brizendine [5, 6], beganto delve into the hormonal processes of a woman's body and discovered that hormones have a huge neurological effect at various stages of a woman's life, shaping her desires, values and perception of reality in general. The action of hormones is felt at every stage of life, from birth. Each of life's hormonal phases - the girl's period, adolescence, maturity $<\ldots>$, motherhood, and menopause stimulates an increasing number of different neural connections, which are responsible for new thoughts, emotions, and interests. New tools such as positron emission tomography (PET) and functional magnetic resonance imaging (fMRA) scans today allow us to look at the human brain in real time $<\ldots>$. The female brain performs all cognitive functions like the male brain, but using other brain links. Looking at the FMRA under a microscope shows that the brain differences between men and women are complex and manifest in many places. For example, in brain centers responsible for speech and hearing, women have 11 percent more neurons than men. The main center of emotion generation and memory formation - the Horn of Ammon - is also larger in women's brains, just as the brain sectors are responsible for speech and observing other people's emotions. The male brain, by contrast, has an area of sexual desire two and a half times larger than the female brain and larger brain centers responsible for activity and aggression. Men have more powerful information processors in their tonsils that respond to fear and promote aggression. That is why it only takes a few seconds for some men to go from a peaceful conversation to a fight $<\ldots>$. However, the psychological stress caused by the conflict deepens in the woman's brain. Women and men have roughly the same intelligence level <... . When girls and boys reachadolescence, their scientific capabilities do not differ. However, as soon as estrogen enters a girl's brain, she begins to focus on emotions and communication - she spends a lot of time on the phone or talking to her friends $<\ldots>$. During the 
same time period, boys' brains experience an influx of testosterone, making them less likely to communicate and more likely to become engrossed in computing mania $<_{\ldots}>$. A teenage girl wants to be loved and belong to society, and a teenage boy feels the need to be respected and occupy a high place in the male hierarchy. As boys and girls consider their career options, girls become unappealing goals, requiring more individual work and less interaction with others, whereas boys tend to $<\ldots>$ distance themselves from the world for long hours and close the room alone with the computer. The effects of hormones on a woman's brain encourage her to seek communication and communication. A woman's brain has many unique tendencies - unparalleled verbal mobility, the ability to maintain intimate and close relationships, an almost extrasensory ability to read facial expressions and the nuances of voice timbre with the ability to quell conflict. All of these properties are biologically embedded in a woman's brain. These female abilities are innate $\langle\ldots\rangle$. Men are born with other abilities that are handled by their hormonal reality. Children's impulses are natural and emanate from within. They burst even when we adults try to tilt them in a different way. Nature is arguably the most important factor influencing gender-specific behaviors, but experience, practice, and interactions with others can also affect neurons and brain connections. $<\ldots>$ Studies show that the genetic susceptibility of men's and women's brains to environmental influences differs. $<\ldots>\mathrm{A}$ person's inclinations and abilities are determined by nature and upbringing: a child's development is inextricably linked to both of these factors. The most common goals that dictate to a little girl's brain $<\ldots>$ are to build bridges of connection, to build a community, to create and sustain her world so that she is at the center of it. This is where female brain aggression is needed - it defends what is important to her, and the most important thing for her is always the sphere of relationships. Aggression helps both sexes to survive, and the brains of both sexes have the necessary links to do so. Girls' aggression is more subtle, reflecting their brain structure more accurately. Men often enjoy conflict and competition; it tones them. In the female brain, the chain of aggression is more closely linked to cognitive, emotional, and verbal functions than aggressively regulating the structure of the male brain, which is closely related to the area of the brain responsible for physical activity. In a stressful situation, men have a 'fight and run' principle, and women have a 'take care and make friends' principle. The emotional centers of a girl's brain become very exciting during adolescence. Her emotional and impulse control system - the cortex of the forehead - has many cells by the age of twelve, but their connections are still weak and immature. A sudden increase in hormone levels during adolescence can turn a minor shock into a major disaster. Teens express their intentions - and experience them - with such great passion that it can break even the armor of your common sense. It must be borne in mind that impulse control circuits are not yet able to cope with avalanche of information that $<_{\text {... }}>$ adolescent $<_{\text {... }}>$ has flooded them. <..> You have to be her impulse regulator because her own brain can not do that yet. Hormones, both for men and women, the commonly associated with aggression, are called androgens. Their level begins to rise at the beginning of puberty, and reaches a maximum at nineteen for girls and twenty-one for boys. The three main androgens produced in a woman's body are testosterone, DHEA and androstenedione. Studies at the University of Utah show that the most prominent teenagers have the highest levels of androgen androstenedione. A sign that $\langle\ldots\rangle$ a teenager's body is rich in androgens, and is rich in acne. Cortisol, a stress hormone, blocks the action of oxytocin in the brain and immediately suppresses a woman's need for contact. <..> Scientists believe that a woman's brain contains more mirror neurons than a man's brain. An increase in estrogen levels means that girls experience inner feelings and pain more strongly than boys do. As brain scan data shows, the areas that capture inner feelings in the female brain are larger and more sensitive. For several years, girls have outperformed boys in understanding how to protect another person's feelings or how one or more characters in a story feels. This ability can be the result of the activity of mirror neurons, allowing girls not only to observe other people's gestures, posture, respiration rate, gaze, and facial expressions, but also to imitate or "reflect" them, thus evoking emotions similar to those they feel. Intuition is a characteristic of women $\langle\ldots>$. In a man's brain, most emotions trigger an inner feeling less, but more rational thoughts. A typical reaction of a man's brain to emotions is to try to avoid them at all costs.

\section{Research Organization and Results}

In order to find out the problems with the subject of technology, a questionnaire survey of students and teachers was conducted in April - June. A total of 800 students were interviewed, including 456 girls and 344 boys, as well as 21 teachers, including 7 males and 14 females. This event drew students from various Lithuanian schools in the fifth, sixth, seventh, eighth, ninth, and tenth grades. The questions that make up the questionnaire are related to the real situation of the technology subject "through the eyes of students", learning in a mixed and non-mixed group.

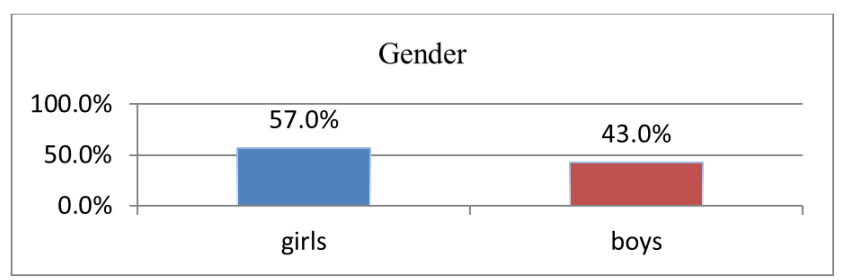

Figure 1. Numbers of girls and boys in the study.

The following answers were received to the question "Do you study technology in a mixed group all year round?": $57.9 \%$ of students study in a mixed group all year round. $42.1 \%$ of students do not study in a mixed group all year round. 
Do students study in a mixed technology group all year round?

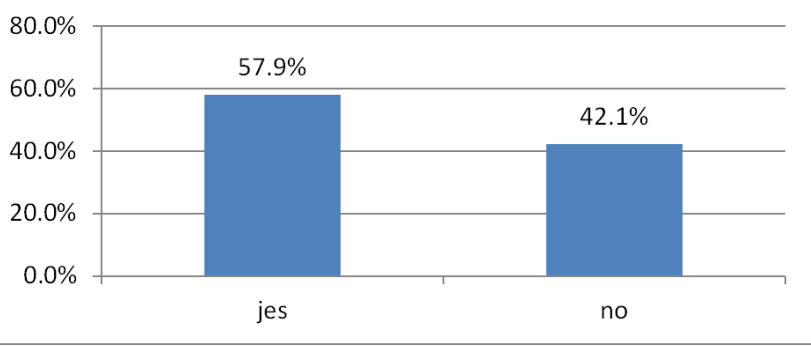

Figure 2. Number of students studying in a mixed group throughout the year.

Both Lithuanian authors and foreign researchers consider the issue of learning motivation to be one of the most important issues in the teaching and learning process. The following answers were asked to the question "In your opinion, is learning motivation stronger and results better in a technological mixed group or a non-mixed group?": $37.9 \%$ of students state that learning motivation is stronger and results better in technology mixed group and $62.1 \%$ of students say that learning motivation is stronger and theresults are better when learning technology in a non-mixed group. A relatively large proportion of students $(62.1 \%)$ believe that learning motivation is stronger and the results are better when learning technologies in a non-mixed group.

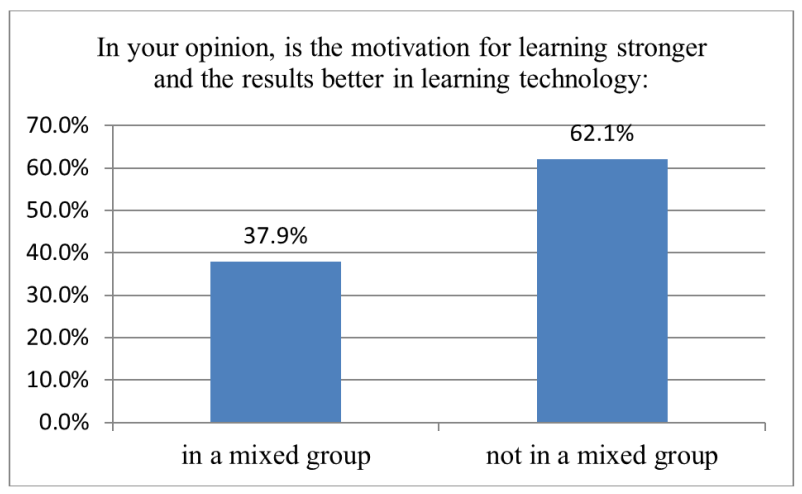

Figure 3. Learning motivation.

When asked what students value most in technology subject programs and how they rate them, $80.8 \%$ of students answered that they evaluate nutrition positively, $19.2 \%$ negatively evaluate nutrition; $23.5 \%$ of students evaluate textiles positively, $76.5 \%$ of students evaluate textiles negatively; $32.5 \%$ of students evaluate the construction materials program ("rougher" jobs where more muscle strength is required) positively and $67.5 \%$ of students evaluate it negatively; $24.9 \%$ of students evaluate the program of construction materials ("softer" jobs where less muscle strength is required) positively, $75.1 \%$ of students evaluate it negatively; $29.5 \%$ of students evaluate electronics positively, $70.5 \%$ of students evaluate electronics negatively.

To the question, "Do you support a technology program that considers the "nature" and learning differences of boys and girls?" $87.4 \%$ of students said they supported the program and only $12.6 \%$ of students said they did not. Therefore, it can be concluded that the "nature" that influences teaching is important for students.
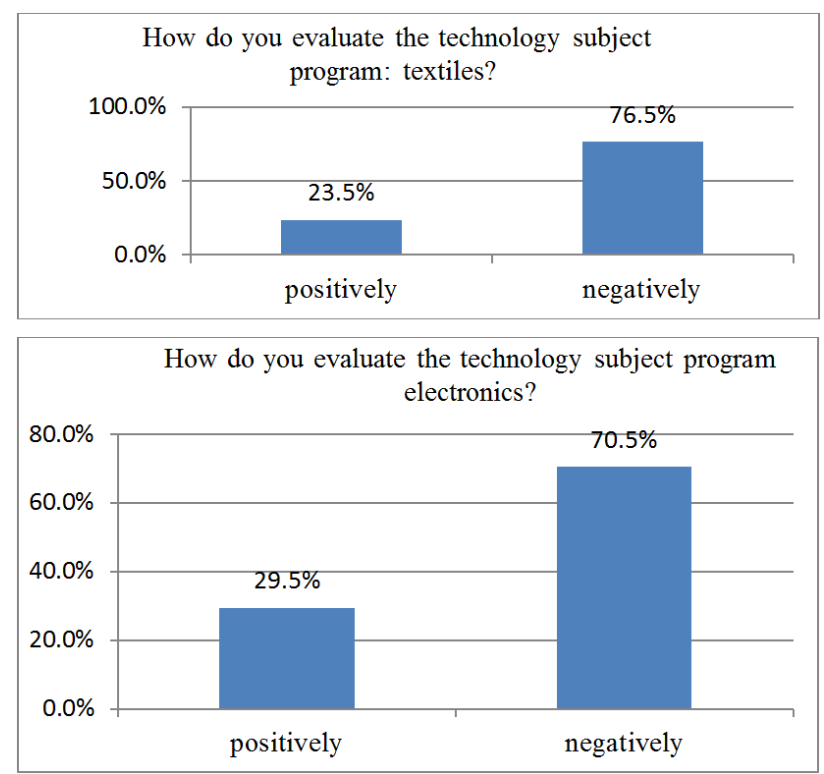

Figure 4. Evaluation of technology subject programs.

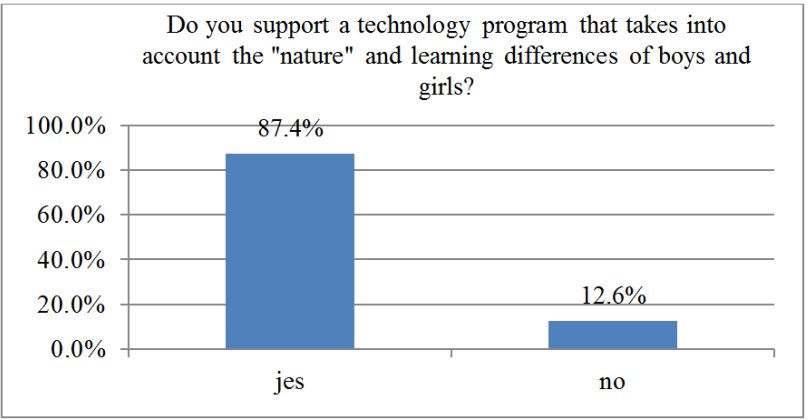

Figure 5. An evaluation of a technology program that takes into account the nature and learning differences of boys and girls.

The survey also revealed, "What do boys and girls value most in technology subject programs, and how do they differ?"91.0\% of girls evaluate the nutrition program positively and $9.0 \%$ evaluate it negatively; $67.2 \%$ of boys evaluate "nutrition" positively and $32.8 \%$ evaluate "nutrition" negatively.

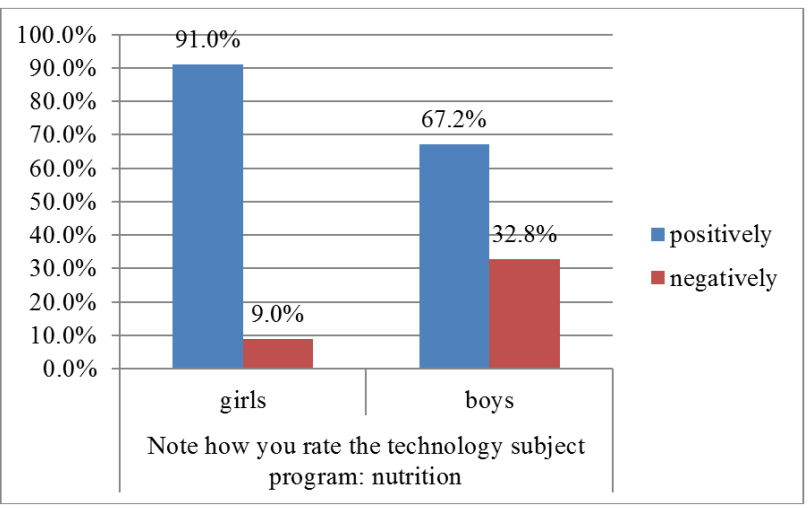

Figure 6. Technology subject program evaluation. 
$33.3 \%$ of girls evaluate the textile program positively and $66.7 \%$ evaluate it negatively; only $10.5 \%$ of boys evaluate their diet positively and $89.5 \%$ evaluate it negatively.

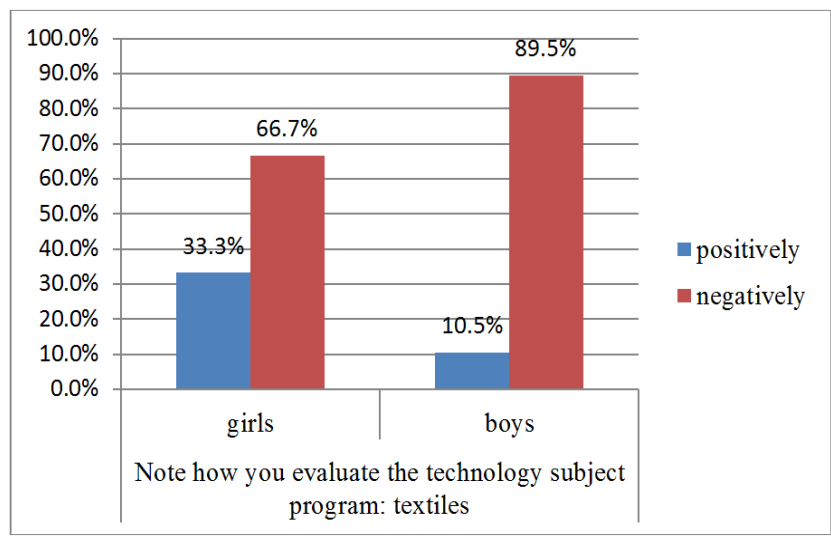

Figure 7. Technology subject program evaluation.

$18.6 \%$ of girls evaluate the program of construction materials ("rougher" works) positively and $81.4 \%$ evaluate it negatively; $50.9 \%$ of boys evaluate this program positively and $49.1 \%$ evaluate it negatively.

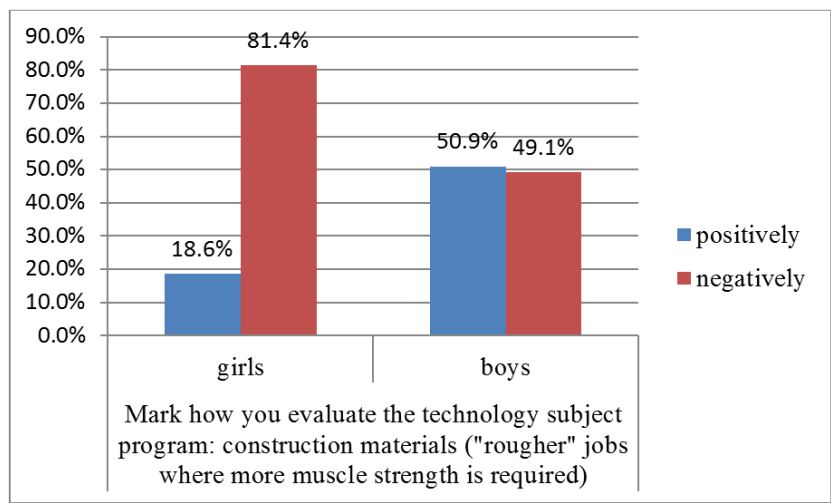

Figure 8. Technology subject program evaluation.

$33.6 \%$ of girls evaluate the program of construction materials ("softer" work) positively and $66.4 \%$ evaluate it negatively; $13.4 \%$ of boys evaluate this program positively and $86.6 \%$ evaluate it negatively.

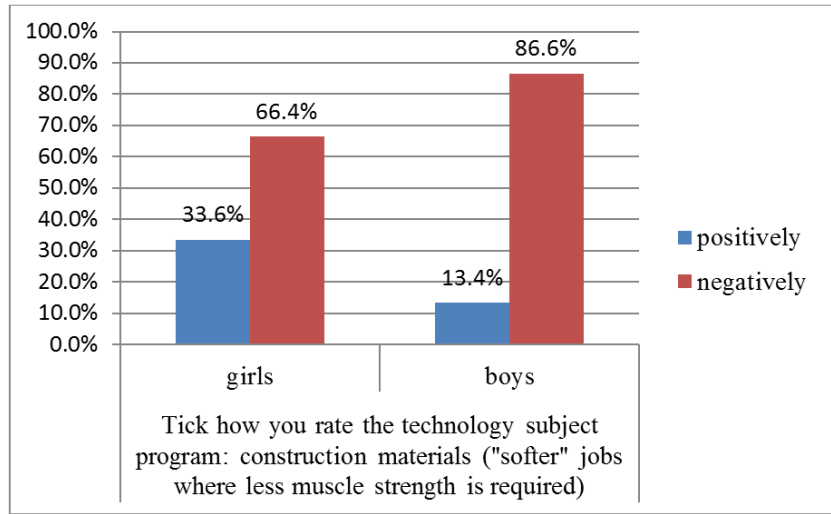

Figure 9. Technology subject program evaluation.
$15.4 \%$ of girls evaluate the electronics program positively and $85.6 \%$ evaluate it negatively; $48.3 \%$ of boys evaluate this program positively and $51.7 \%$ evaluate it negatively.

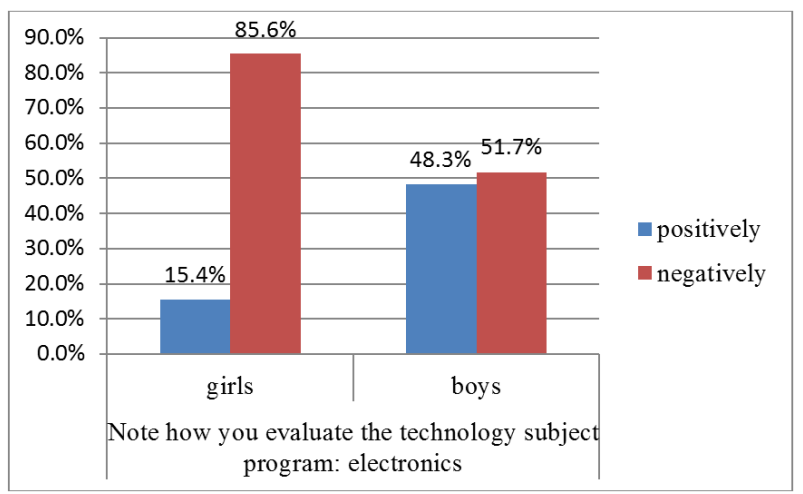

Figure 10. Technology subject program evaluation.

$38.6 \%$ of girls say that learning motivation is stronger in the mixed group of better learning technologies and $61.4 \%$ in the non-mixed group. $36.9 \%$ of boys state that learning motivation is stronger and better when learning technology in the mixed group and $63.1 \%$ in the non-mixed group.

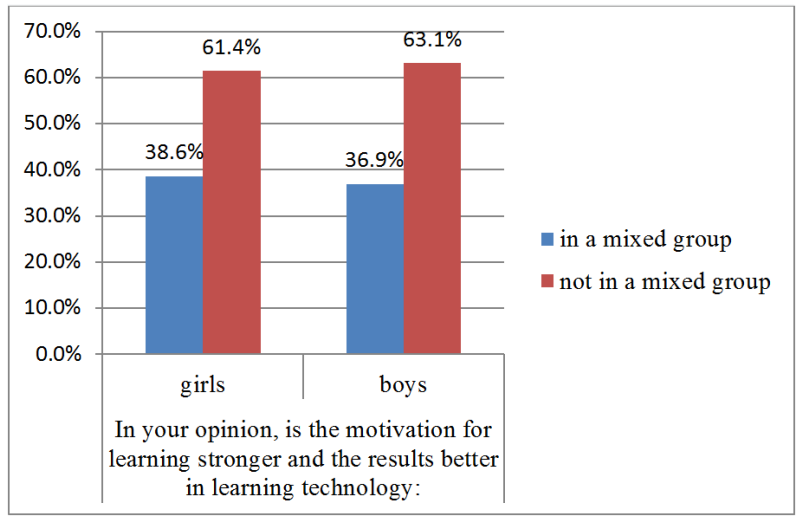

Figure 11. Learning motivation.

$84.0 \%$ of girls support a technology program that takes into account the nature and learning differences of boys and girls and $16.0 \%$ do not. Also, $91.9 \%$ of boys support a technology program that takes into account the nature and learning differences of boys and girls, and $8.1 \%$ do not.

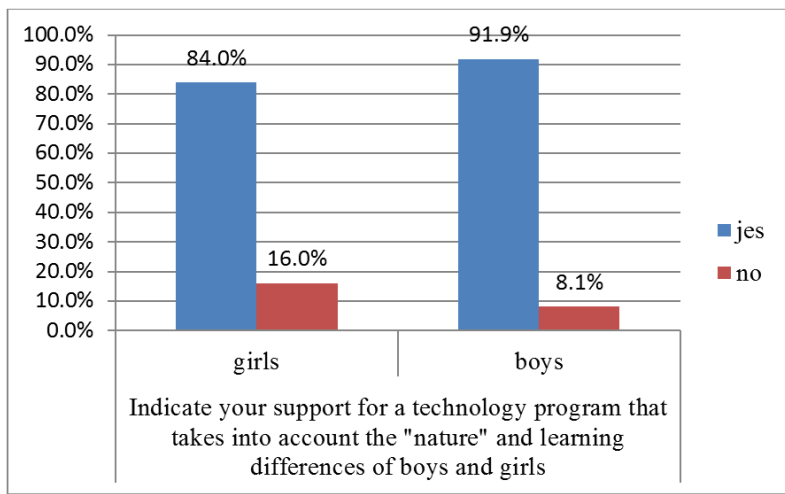

Figure 12. An evaluation of a technology program that takes into account the nature and learning differences of boys and girls. 
Therefore, it can be concluded that for students of both sexes, their "nature" is important, which influences teaching.

\section{Conclusions}

1. A person's inclinations and abilities are determined by nature and upbringing: a child's development is inextricably linked to both of these factors. Nature is the most important factor influencing gender-specific behavior, but experience, practice, and interaction with others also affect neurons and brain connections. The female brain performs all cognitive functions like the male brain, but using other brain links. Studies show that the genetic susceptibility of men's and women's brains to environmental influences differs.

2. The change of educational paradigms - teaching (impact), interaction and learning - is directly related to the teacher's work style, teaching goals, methods, teaching / learning environment, teacher-student interaction, as well as educational documents regulating general education.

3. There is a lack of time for the full implementation of the curriculum (teachers are burdened with "unnecessary" activities) and methodological materials, dissemination of information, as well as the material base and funding are insufficient.

4. The subject of technology is the only thing whose change in content has helped to identify the naturally different teaching (learning) of boys and girls and to draw attention to the differences in their teaching and learning achievements in other subjects as well. For many years, differences in teaching and learning have existed in Lithuanian and international schools. There have been significant differences in the learning achievements of girls and boys in the country and around the world over the last 17 (seventeen) years (2002-2018).

5. A 2018 survey found that $87.4 \%$ of students support a technology program that takes into account the "nature" and learning differences of boys and girls. Only $12.6 \%$ of students do not support this program.

6. The following problematic areas of the technology subject have been identified: 1$)$ textile program $(23.5 \%$ per cent). The programs for construction materials are evaluated the lowest: (32.5\% per cent).

7. A higher proportion of students $(62.1 \%)$ say that learning motivation is stronger and the results are better when learning technologies in different gender groups.

\section{Recommendations}

Coordinated efforts should be made in Lithuania and around the world to encourage boys and girls to reach their full potential. It is therefore necessary to change the education strategy. Experience in OECD countries shows that there are a number of steps that can be taken to close the gap in learning outcomes between girls and boys: Look for methods of learning to interest boys and girls, taking into account their inherent characteristics. Reduce the study load in subjects, give up homework or replace homework with creative projects or long-term tasks. Stop forming a "fear" attitude towards science for students that from the first grade they are prepared for exams in the twelfth grade. In all subjects, the tasks of the Olympiads must be designed purposefully: for the age group and class of the students, taking into account the subject programs. To the effect that teachers do not teach students "forward" because children's brain circuits have a certain period of puberty and are psychologically unprepared for information and workload not according to their age. Introduce a reading and writing skills development program in schools that would improve students' comprehension and writing skills and the quality of teaching and learning. To modernize the curriculum in order to foster scientific potential in higher education institutions, as well as to train top-tier teachers.

\section{Summary}

A person's inclinations and abilities are determined by nature and upbringing. A child's development is inextricably linked to both of these factors. Nature is the most important factor influencing gender-specific behavior, but experience, practice, and interaction with others also affect neurons and brain connections. The female brain performs all cognitive functions like the male brain, but using other brain links. Studies show that the genetic susceptibility of men's and women's brains to environmental influences differs. Changes in educational paradigms - teaching (impact), interaction and learning - are directly related to the teacher's work style, teaching goals, methods, teaching/learning environment, teacher-student interaction, as well as educational documents regulating general education. According to the IEA TIMSS, IEA PIRLS, MESS (Ministry of Education, Science and Sport), NMPT, NEC studies, over 17 (seventeen) (2002 2018) years, there have been significant differences in the learning achievements of girls and boys in the country and in the world. In Lithuania, girls tend to achieve better learning outcomes (especially there is a large gap between boys and girls reading skills). There is currently a lack of subject didactics research to help understand how to effectively teach different subjects to students of different genders. In Lithuania, as in most European countries, there are areas of education where it is necessary to take more care of girls' learning opportunities, but in other areas, boys' learning is more of a concern. Technology lessons and studies are a great medium to encourage students' (young people's) creative beginnings, develop their creativity, positive thinking, implement moral values and strengthen motivation for science. The subject matter of technology in various aspects has been studied by different scientists for many years. Looking at the "history" of the subject of technology, it can be stated that it lost the interest of students during the change in the curriculum of the subject. The noble goal of "preserving the subject" is achieved in various ways: by 
reorganizing the curriculum in university and school learning programs. Creating only mixed groups of students did not preserve technology at university and decreased learning motivation among pupils and students. The subject of technology is the only thing whose change in content has helped to refine the natural teaching (learning) of boys and girls and to draw attention to the differences in their teaching and learning achievements in other subjects as well. For many years, differences in teaching and learning have existed in Lithuanian and international schools. In order to find out the problems with the subject of technology, a questionnaire survey of students and teachers was conducted in 2018. A total of 800 students were interviewed: 456 girls and 344 boys, 21 teachers: 7 males and 14 females. This event drew students from various Lithuanian schools in the fifth, sixth, seventh, eighth, ninth, and tenth grades. The survey found that $87.4 \%$ of students support a technology program that takes into account the "nature" and learning differences of boys and girls. Only $12.6 \%$ of students do not support this program. Therefore, it can be concluded that their "nature" which influences teaching is important to students. The following technological problem areas were also identified: 1) textile program $(23.5 \%$ per cent $)$, programs for construction materials are evaluated the lowest: $(32.5 \%$ per cent). A higher proportion of students $(62.1 \%)$ have stated that learning motivation is stronger and the results are better when technology is being learned by different gender groups. Coordinated efforts should be made in Lithuania and around the world to encourage boys and girls to reach their full potential. Experience in OECD countries shows that some action can be taken to close the gap in learning outcomes between girls and boys. There is a need to look for ways to get boys and girls interested in learning subjects. Reduce the study load in subjects, give up homework or replace homework with creative projects or long-term tasks. Stop forming a "fear" attitude towards science for students who are being prepared for their twelfth grade exams from the first grade. Consider the preparation for the school Olympics. In all subjects, the tasks of the Olympics must be designed purposefully: for the age group and class of the students, taking into account the subject programs. To achieve this goal, teachers shouldn't teach students "in advance" because children's brain circuits have a certain period of puberty and are psychologically unprepared for information and work that is more complex than students are able to understand. Introduce a reading and writing skills program in schools that would improve students' comprehension and writing skills and the quality of teaching and learning. While updating the curriculum, it seeks to develop the scientific potential of the higher education institutions that train teachers on this topic.

\section{References}

[1] Baron-Cohen S. Substantial Difference. Male and female brains.- Vilnius: UAB Baltų lankų leidyba, 2011.- 278 p.
[2] Butler T., Pan H., ir kt., "Fear-related activity in subgenual anterior cingulate differs between men and women", Neuroreport 16 (11), 2005, 1233-1236.

[3] Bloch M., Rubinow D., ir kt., "Cortisol response to ovine corticotropin-releasing hormone in a model of pregnancy and parturition in euthymic women with and without a history of postpartum depression", J Clin Endocrinol Metab 90 (2), 2005, 695-699.

[4] Britton E., De Long-Cotty B., Levenson T. (2005). Bringing Technology Education into K-8 Classrooms: a Guide to Curricular Resources about the Designed World. Thousand Oaks, CA: Corwin Press.

[5] Brizendine L. A woman's brain. - Vilnius: UAB Baltoslankos, 2006.- 279 p.

[6] Brizendine L. The Female Brain.- New York, 2006.- 279.

[7] Brebner J. "Gender and emotions", Personality and Differences 34, 2003, 387-394. Cahill L., "Sex-related influences on the neurobiology of emotionally influenced memory", AnnNyAcadSci 985, 2003, 163-173.

[8] Cahill L., "His brain, her brain", Sci Am 292 (5), 2005, 40 47.

[9] Gray J. Men, Women and Relationships.- Vilnius: Alma littera, 2018.- $285 \mathrm{p}$.

[10] Girdzijauskienė R., Gudynas P., Jakavonytė D., Jevsikova T. Application of Innovative Teaching Methods and ICT. A methodological tool for primary school teachers and special educators. - Vilnius: UAB Sapnų sala, 2010. - 97 p.

[11] Gudynas P., Bigelienė D., Dargytė J., Melnikė E., Skripkienė R. 2014 national surveys of students' achievements. Report. [Interactive]. Access through internet:<http://www.nec.lt/failai/6057_2014_NMPT_ataskait a_galutine_RED.pdf. $>$.

[12] Gudynas P., Bigelienè D., Šidlauskytė G., Dargytė E., Skripkienè R. National surveys of students' achievements in 2015. [Interactive]. Access through internet: $<$ http://www.nec.lt/failai/6728_2015_NMPT_ataskait a.pdf $>$.

[13] Gudynas P., Vingelienè S., Bigelienė D., Melnikė E., Davolytė J., Skripkienè R. 2018. The results of the national review of student achievement, the findings and recommendations of the data analysis. [Interactive]. Access through internet: $<$ http://www.pavilnys.vilnius.lm.lt/wpcontent/uploads/2018/01/NMPP-2018-m.-rezultatai-2.pdfs.

[14] Goldstein J., Jerram M., ir kt., "Hormonal cycle modulates arousal circuitry in women using functional magnetic resonance imaging", J Neurosci 25 (40), 2005, 9309-9316.

[15] Grant Y., Grant M. My daughter is growing! How to raise a true Woman. - Minsk: Potpourri, 2014.-272 p.

[16] Grant Y., Grant M. My son is growing! How to raise a real Man. -Minsk: Potpourri, 2015. - 288 pages.

[17] Kaufman J., Vermeulen A., "The decline of androgen levels in elderly men and its clinical and therapeutic implications", Endocr Rev 26 (6), 2005, 833-876.

[18] Pease A., Pease B. Why men can't find the keys and women still need new shoes. Vilnius: Alma litera, 2016. - 364 p. 
[19] Pease A., Pease B. Why men do not listen and women do not orient themselves on maps. Vilnius: Alma litera, 2016. - 297 p.

[20] Pendergast, D., Mc Gregor, S. L. T., Turkki K. (2012) Greating Home Economics Futures: the next 100 Years. Bowen Hills: Ausralian Academic Press. 228 p.

[21] Petty G. Evidence-Based Training. Practical guide.- Vilnius: Tytoalba, 2008. - 494 p.

[22] Phelps E. "Human emotion and memory: Interactions of the amygdala and hippocampal complex", CurrOpinNeurobiol 14 (2), 2004, 198-202.

[23] Kring A. "Gender and anger", pagrindinisšaltinis: Gender and Emotion: Social Psychological Perspectives: Studies in Emotion and Social Interaction, ed. A. H. Fischer, 2nd series (211-31), New York: Cambridge University Press, 2000.

[24] Kendler K., Gatz M., ir kt., "A Swedish national twin study of lifetime major depression", Am J Psychiatry 163 (1), 2006, $109-114$.

[25] Juralovič M., (2018). Changing the content of the subject of technology. Social education, vol. 50, p. 68-86.

[26] Kvieskienė G., (2015). Smart education - for social industries. Social education, vol. 41, p. 5-16.

[27] LRŠMM. Implementation of the State Education Strategy for 2013-2022. (2015). [Interactive]. Internet access: $<$ https://www.smm.lt/uploads/lawacts/docs/687_990ea 392c0adc4c25c657236b66583c4.pdf $>$.

[28] LRŠMM. ANALYSIS OF THE EDUCATION PROBLEM. ARE COMPULSORY EDUCATION OPPORTUNITIES FOR BOYS AND GIRLS ENSURED IN LITHUANIA (2009) [Interactive]. Accessvia the Internet: $<$ https://nec.lt/failai/3960_Lygios_galimybes.pdf>.

[29] Lapukauskas V., Lapukauskiene T. The Wisdom of a Man. Vilnius: UAB Luceo, 2018- 245 p.

[30] Lekavičienė R., Vasiliauskaitè Z., Antinienè D., Almonaitienė J. Communication psychology in modern times.- Vilnius: Alma litera, 2018. - 439 p.
[31] Leresche L., Mancl L., ir kt., "Relationship of pain and symptoms to pubertal development in adolescents", Pain 118 (1-2), 2005, 201-209.

[32] Lobo R. Menopause, San Diego: Academic Press, 2000.

[33] Li R., Shen Y., "Estrogen and brain: Synthesis, function and diseases", Front Biosci 10, 2005, 257-267.

[34] Nagy E., "Different emergence of fear expression in infant boys and girls", Infant Behavior and Development 24, 2001, 189-194.

[35] Numgaudienè A., Žygaitienè B. (2014). Analysis of the content of technology teacher training programs in European countries // Pedagogy. P. 112-120.

[36] Numgaudienè A., Ramanauskaitė A. (2014). Application of innovative teaching / learning methods in the subject of technology in developing students' creativity: empirical insights [Interactive]. Access via the Internet: $<$ https://eltalpykla.vdu.lt/bitstream/handle/1/465/ISSN20298447_2014_N_24.PG_110-117.pdf?sequence= 1 \& isAllowed $=\mathrm{y}>$.

[37] Simon R., "Gender and emotion in the United States", American Journal of Sociology 109, 2004, 1137-1176.

[38] Samter W., "How gender and cognitive complexity influence the provision of emotional support: A study of indirect effects", Communication Reports: Special psychological mediators of sex differences in emotional support 15 (1), 2002, 5-16.

[39] Skurvydas A. Modern Neurorabilitation: Movement Management and Mind Training. [Interactive]. Internet access: $<$ https://www.lsu.lt/sites/default/files/dokuumentai/Modernioji $\% 20$ neuroreabilitacija.pdf $>$.

[40] Tessitore A., Hariri A., ir kt., "Functional changes in the activity of brain regions underlying emotion processing in the elderly", Psychiatry Res 139 (1), 2005, 9-18.

[41] Wager T., Phan K., ir kt., "Valence, gender, and lateralization of functional brain anatomyin emotion: A meta-analysis of findings from neuroimaging", Neuroimage 19 (3), 2003. 